\title{
EFEK PENGGUNAAN SOFTWARE GEOGEBRA PADA PADA PEMAHAMAN KONSEP DITINJAU DARI GAYA BELAJAR
}

\author{
Syaiful Huda ${ }^{1}$, Fatimatul Khikmiyah ${ }^{2}$ \\ Universitas Muhammadiyah Gresik ${ }^{1}$ \\ syaifulhuda@umg.ac.id \\ Universitas Muhammadiyah Gresik ${ }^{2}$ \\ fatim@umg.ac.id
}

\begin{abstract}
Abstrak
Sifat dari mata kuliah kapita selekta matematika yang merupakan mata kuliah dengan pengayaan pada matematika sekolah menengah atas, diperlukan sesuatu yang lebih bisa digunakan untuk membantu pemahaman mahasiswa. Teknologi informasi dan komunikasi juga dapat digunakan sebagai media pembelajaran. Menurut Hohenwarter (2008), Geogebra adalah software yang digunakan untuk pembelajaran matematika, khususnya geometri dan aljabar. Tujuan dari penelitian ini adalah untuk mengetahui efek dari penggunaan software Geogebra pada pemahaman konsep dalam mata kuliah kapita selekta matematika atas ditinjau dari gaya belajar. Metode yang digunakan adalah pretestintervention-posttest.

Hasil yang diperoleh adalah untuk gaya belajar kinestetik terdapat efek berdasarkan uji t yang dilakukan $(\mathbf{0 , 0 0 3}<\boldsymbol{\alpha}(\mathbf{0 , 0 5}))$. Sedangkan untuk gaya belajar Visual tidka ada efek, hal tersebut didasarkan pada uji t yang dilakukan yaitu $(\mathbf{0 , 0 8 0}>\boldsymbol{\alpha}(\mathbf{0 , 0 5}))$. Untuk gaya belajar Auditori tidak dapat dilakukan uji-t karena hanya satu nilai (datum).
\end{abstract}

Katakunci: Efek, Geogebra, Kinestetik, Visual, auditori

\begin{abstract}
Abstrack
The nature of the course of mathematics capita which is a course with enrichment in high school mathematics, something more can be used to help students understand. Information and communication technology can also be used as a learning medium. According to Hohenwarter (2008), Geogebra is software used for learning mathematics, especially geometry and algebra. The purpose of this study was to determine the effects of the use of Geogebra software on understanding concepts in the course of learning in the upper mathematics in terms of learning styles. The method used was pretest-interventionposttest.

The results obtained are for kinesthetic learning styles there are effects based on the t test $(0.003<\alpha(0.05))$. Whereas for the Visual learning style there are no effects, it is based on the $t$ test which is done (0.080> $\alpha(0.05))$. For Auditory learning styles, the t-test cannot be done because there is only one value (datum).
\end{abstract}

Keywords: Effect, Geogebra, Kinestetic, Visual, Auditory

\section{PENDAHULUAN}

Buku ajar mempunyai peranan yang sangat penting dalam pembelajaran. Menurut Greene dan Petty (1981) memberikan beberapa peranan buku ajar sebagai berikut: (1) Pencerminan sudut pandang yang kuat dan modern mengenai pengajaran serta mendemontrasikan aplikasi dalam bahan pengajaran yang disajikan. 
Menyajikan suatu sumber pokok masalah atau subject matter yang kaya, mudah dibaca dan bervariasi, yang sesuai dengan minat dan kebutuhan para siswa, sebagai dasar bagi program-program kegiatan yang disarankan di mana keterampilanketerampilan ekspresional diperoleh pada kondisi yang menyerupai kehidupan yang sebenarnya. Menyediakan suatu sumber yang tersusun rapi dan bertahap mengenai keterampilan-keterampilan ekspresional. (4) Menyajikan (bersama-sama dengan buku manual yang mendampinginya) metode-metode dan sarana-sarana pengajaran untuk memotivasi siswa. (5) Menyajikan fiksasi awal yang perlu sekaligus juga sebagai penunjang bagi latihan dan tugas praktis. (6) Menyajikan bahan atau sarana evaluasi dan remedial yang serasi dan tepat guna.

Melihat peranan buku ajar yang ada di atas, sangat perlu adanya pengembangan dalam mata kuliah yang ada di Prodi pendidikan Matematika FKIP-Universitas Muhammadiyah Gresik. Kapita Selekta Matematika Menengah Atas merupakan mata kuliah yang ada pada semester 2 (dua) di prodi pendidikan matematika. Buku ajar kapita selekta matematika atas yang ada saat ini masih merupakan buku ajar cetak. Setiap benda pasti mempunyai kelebihan dan kekurangan, begitu juga pada buku ajar cetak, kelebihan yanga ada adalah: (1) Mudah diperoleh dan dibawa kemana-mana; (2) Mudah dipelajari kapanpun dan dimanapun; (3) Tidak memerlukan alat khusus untuk menggunakannya; (4) Pengirimannya relative mudah dan murah dibanding media lainnya; (5) Merupakan media yang paling canggih untuk mengambangkan kemampuan siswa untuk belajar tetang fakta dan prinsip-prinsip umum serta abstrak dengan menggunakan argumentasi yang logis.

Sedangkan kekurangan yang dimiliki pada buku ajar cetak adalah: (1) Kekurangan bahan ajar cetak; (2) Tidak mampu mempresentasikan gerakan; (3) Pemaparan materi dalam bahan ajar cetak cenderung linier; (4) Tidak mampu mempresentasikan kejadian secara berurutan; (5) Untuk membuat bahan ajar cetak yang bagus, diperlukan biaya yang tidak sedikit; (6) Membutuhkan kemampuan baca yang tinggi dari pembacanya; (7) Tidak dapat atau sulit memberikan bimbingan kepada pembacanya yang mengalami kesulitan memahami bagian tertentu dari bahan ajar tersebut; (8) Sulit untuk memberikan umpan balik untuk pertanyaan-pertanyaan kompleks yang 
memiliki kemungkinan banyak jawaban.

Dengan sifat dari mata kuliah kapita selekta matematika yang merupakan mata kuliah dengan pengayaan pada matematika sekolah menengah atas, diperlukan sesuatu yang lebih bisa digunakan untuk membantu pemahaman mahasiswa. Perkembangan teknologi informasi dan komunikasi dapat digunakan sebagai solusi untuk megurangi buka ajar cetak. Pengembangan Buku Ajar kapita selekta matematika menengah atas berbasis IT sangat diperlukan untuk menunjang perkuliahan. Pengembangan Buku Ajar ini sekaligus bertujuan untuk memberikan pengetahuan kepada mahasiswa tentang peran teknologi informasi dan komunikasi dalam proses pembelajaran matematika. Teknologi informasi dan komunikasi juga dapat digunakan sebagai media pembelajaran.

Salah satu program komputer (software) yang dapat digunakan sebagai media pembelajaran matematika adalah Geogebra. Menurut Hohenwarter (2008), Geogebra adalah software yang digunakan untuk pembelajaran matematika, khususnya geometri dan aljabar. Berdasarkan penelitian Suweken (2011), diperoleh bahwa penggunaan software Geogebra bersifat multi-representasi, yaitu adanya tampilan aljabar, (ii) adanya tampilan grafis, (iii) adanya tampilan numerik, serta ketiga tampilan tersebut terhubung secara dinamik.

Dari hal-hal yang telah dipaparkan sebelumnya maka peneliti akan melakukan penelitian Efek Penggunaan Software Geogebra pada Mata Kuliah Kapita Selekta Matematika Atas Ditinjau dari Gaya Belajar.

\section{METODE}

\section{Pretest-Intervention-Posttest}

adalah metode yang digunakan untuk mengetahui efek dari inovasi pembelajaran yang biasanya digunakan dalam penelitian pendidikan(Dugard \& Todman, 1995). Penelitian ini tidak bertujuan untuk mencari keuntungan atau kerugian dari penggunaan software geogebra pada mata kuliah kapita selekta matematika atas tetapi untuk mengetahui efek dari software geogebra dalam peningkatan pemahaman konsep pada mata kuliah kapita selekta matematika atas.

Prosedur dan intervensi

Diawal penelitian, mahasiswa diberika pretest dan angket gaya belajar. Kemudian diberikan kegiatan untuk penggunaan software geogebra yang diimplementasikan selama 3 SKS dan 7 minggu. Selama penelitian, 
peneliti sebagai dosen di kelas. Setelah

yang disebut posttest.

7 minggu, mahasiswa diberikan tes

Tabel 1. Jadwal kegiatan sebagai berikut.

\begin{tabular}{|l|l|}
\hline Minggu ke- & Kegiatan \\
\hline 1 & Pre Test dan Pemberian Angket Gaya Belajar. \\
\hline 2 & Pembelajaran Geogebra Bentuk Umum \\
\hline 3 & Pembelajaran Geogebra 2D \& 3D \\
\hline 4 & Pembelajaran Geogebra CAS \\
\hline 5 & Logaritma \\
\hline 6 & Eksponen \\
\hline 7 & Fungsi Pecah \\
\hline 8 & Posttest \\
\hline
\end{tabular}

\section{HASIL DAN PEMBAHASAN}

Berikut ini diberikan hasil pembelajaran yang dilakukan dengan intervensi penggunaan software Geogebra.

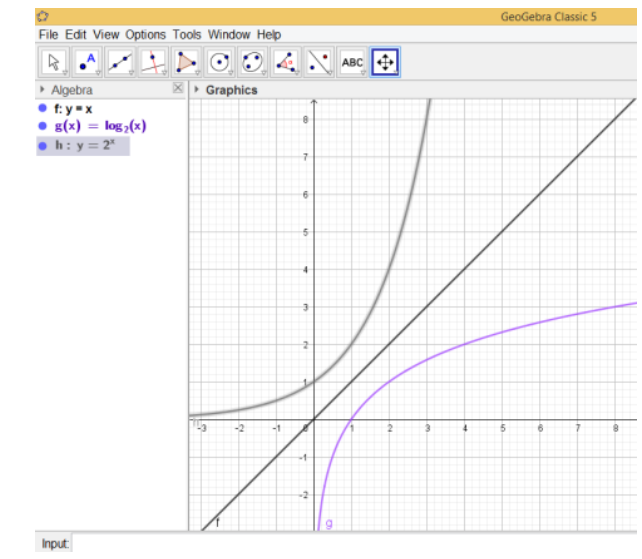

Gambar 1. penggunaan pada visualisasi fungsi grafik eksponen dan logaritma

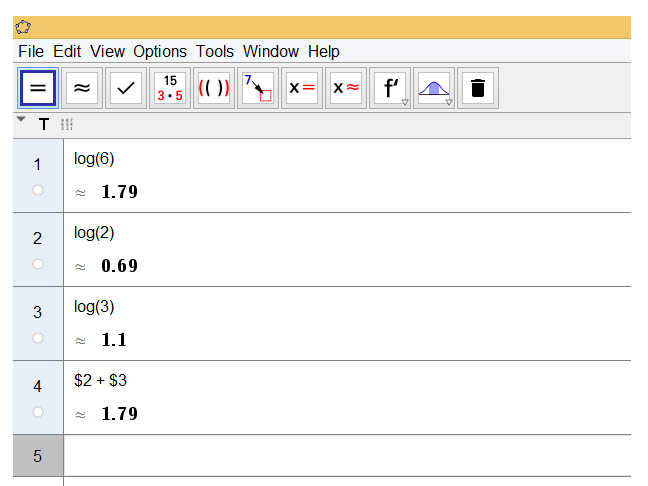

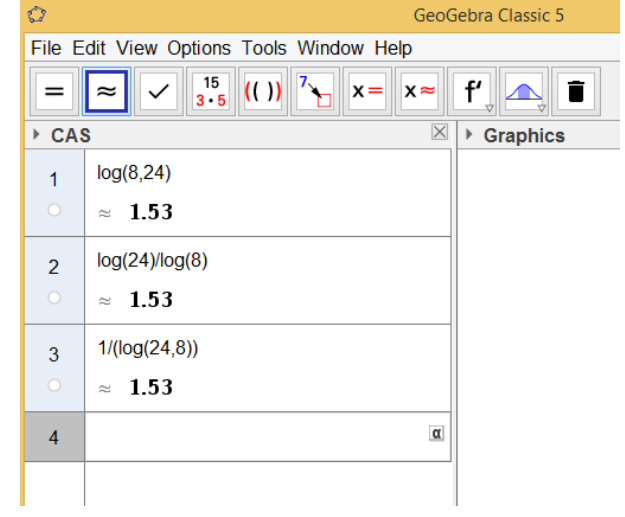

Gambar 2. Penggunaan pada sifat logaritma

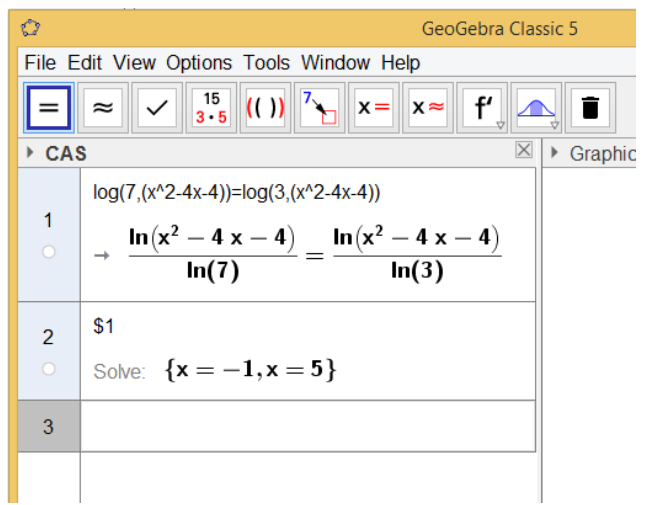

Gambar 3. Penggunaan pada konsep persamaan logaritma

Berdasarkan langkah awal, Mahasiswa diberikan pretest untuk mengetahui pemahaman konsep 
matematika pada mata kuliah kapita selekta matematika atas sebelum dan sesudah intervensi.

Deskripsi statistik dari data sebelum dan sesudah intervensi ditinjau dari gaya belajar .

Tabel 2. Deskripsi Statistik Sebelum \& Sesudah Intervensi ditinjau dari gaya belajar

\begin{tabular}{|l|l|l|l|l|l|l|l|l|}
\hline & \multicolumn{9}{|l|}{ Pretest } & \multicolumn{3}{l|}{ Posttest } \\
\hline & Min & Max & Mean & SD & Min & Max & Mean & SD \\
\hline Kinestetik & 50,00 & 93,00 & 76,5333 & 10,96797 & 58,46 & 100,00 & 85,8905 & 10,42502 \\
\hline Visual & 50,00 & 91,10 & 75,5235 & 14,18809 & 53,84 & 100,00 & 83,0518 & 11,25663 \\
\hline Auditori & 56,70 & 56,70 & 56,7 & 0 & 67,5 & 67,5 & 67,5 & 0 \\
\hline
\end{tabular}

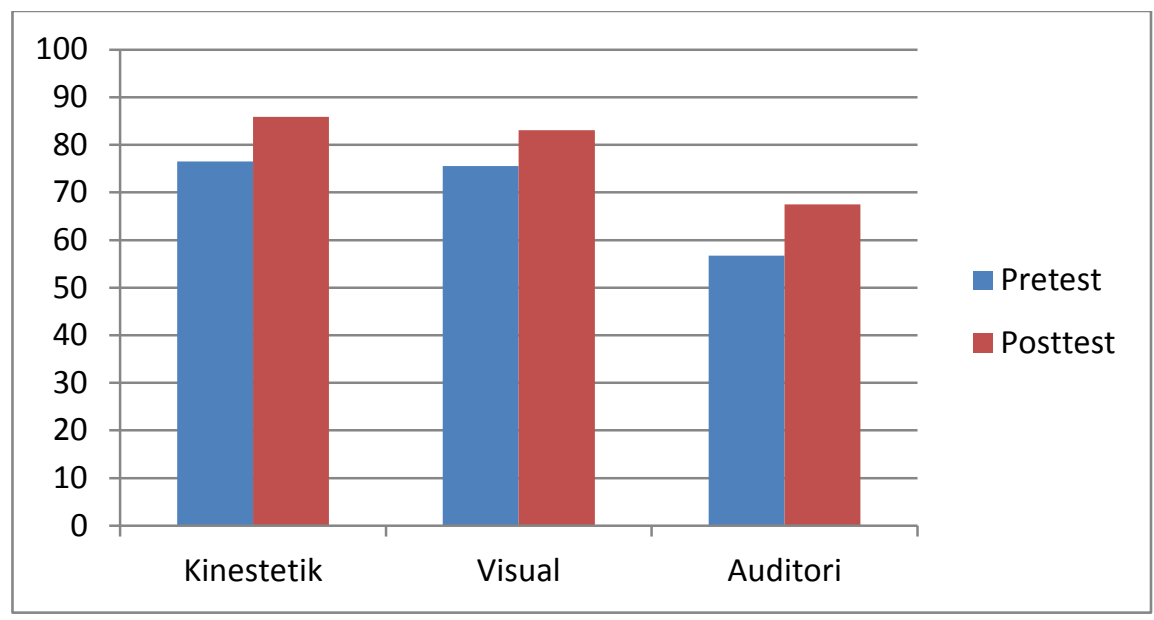

Gambar 4. Grafik Rata-rata per Gaya Belajar

Dari tabel 2 dan Gambar 1. Diperoleh hasil bahwa ketika pretest (sebelum intervensi) Subjek dengan Gaya belajar Kinestetik memiliki ratarata tingkat pemahaman konsep paling tinggi yaitu 76,533 dan Gaya belajar Auditori merupakan yang terendah yaitu 56,7.

Ketika dilakukan intervensi (postest) Subjek dengan Gaya belajar Kinestetik memiliki rata-rata tingkat pemahaman konsep paling tinggi yaitu 85,8905 dan Gaya belajar Auditori merupakan yang terendah yaitu 67,5. Pada 39 Mahasiswa yang dijadikan subjek penelitian, diperoleh hasil angket gaya belajar sebagai berikut: 
Tabel 2. Rekapitulasi Hasil Angket gaya Belajar

\begin{tabular}{|c|c|c|c|c|c|c|c|c|}
\hline No & $\begin{array}{l}\text { Gaya } \\
\text { Belajar }\end{array}$ & Subjek & No & $\begin{array}{l}\text { Gaya } \\
\text { Belajar }\end{array}$ & Subjek & No & $\begin{array}{l}\text { Gaya } \\
\text { Belajar }\end{array}$ & Subjek \\
\hline 1 & $\mathbf{K}$ & EW & 1 & $\mathbf{V}$ & VA & 1 & $\bar{A}$ & RNB \\
\hline 2 & $\mathbf{K}$ & FF & 2 & $\mathbf{V}$ & NR & & & \\
\hline 3 & K & VW & 3 & $\mathbf{V}$ & AHM & & & \\
\hline 4 & $\mathbf{K}$ & NW & 4 & $\mathbf{V}$ & DAS & & & \\
\hline 5 & K & WA & 5 & $\mathbf{V}$ & NAD & & & \\
\hline 6 & K & $\mathrm{MH}$ & 6 & $\mathbf{V}$ & AN & & & \\
\hline 7 & $\mathbf{K}$ & SAL & 7 & $\mathbf{V}$ & FF & & & \\
\hline 8 & $\mathbf{K}$ & EA & 8 & $\mathbf{V}$ & MD & & & \\
\hline 9 & $\mathbf{K}$ & AN & 9 & $\mathbf{V}$ & VMP & & & \\
\hline 10 & $\mathbf{K}$ & SI & 10 & $\mathbf{V}$ & $\mathrm{DH}$ & & & \\
\hline 11 & K & IA & 11 & $\mathbf{V}$ & IZH & & & \\
\hline 12 & K & $\mathrm{NU}$ & 12 & $\mathbf{V}$ & FWD & & & \\
\hline 13 & $\mathbf{K}$ & RLM & 13 & $\mathbf{V}$ & SMN & & & \\
\hline 14 & K & SA & 14 & $\mathbf{V}$ & AWN & & & \\
\hline 15 & K & LHS & 15 & $\mathbf{V}$ & NAR & & & \\
\hline 16 & K & $\mathrm{NF}$ & 16 & $\mathbf{V}$ & MSR & & & \\
\hline 17 & $\mathbf{K}$ & AWA & 17 & $\mathbf{V}$ & IAF & & & \\
\hline 18 & $\mathbf{K}$ & $\mathrm{LN}$ & & & & & & \\
\hline 19 & $\mathbf{K}$ & $\bar{M}$ & & & & & & \\
\hline 20 & $\mathbf{K}$ & $\mathrm{NN}$ & & & & & & \\
\hline 21 & $\mathbf{K}$ & NAR & & & & & & \\
\hline
\end{tabular}

sig $(2$-tailed) $<$ dari $\alpha$ yaitu $0,003<$

Dari rekapitulasi hasil angket gaya belajar, terdapat 21 Mahasiswa dengan gaya belajar Kinestetik, 17 Belajar dengan gaya belajar Visual, dan 1 mahasiswa dengan gaya belajar Auditori.

Dari tabel diperoleh bahwa pada Kinestetik terdapat perbedaan karena
0,05. Tetapi pada gaya belajar Visual tidak ada perbedaan sebelum dan sesudah intervensi penggunaan software geogebra karena sig (2-tailed) $>$ dari $\alpha$ yaitu $0,080>0,05$. Sedangkan untuk Auditori, akrena hanya satu nilai maka tidak bisa dilakukan proses uji t. 

Tabel 3. Hasil Uji t

\begin{tabular}{|c|c|c|c|c|}
\hline & $\mathrm{N}$ & $\mathrm{df}$ & $\mathrm{t}$ & $\mathrm{p}$ \\
\hline Pair 1 Kinestetik & 21 & 20 & $-3,394$ & 0,003 \\
\hline Pair 2 Visual & 17 & 16 & $-1,872$ & 0,080 \\
\hline Pair 3 Auditori & \multicolumn{4}{|c}{ Tidak bisa diproses } \\
\hline
\end{tabular}

\section{PENUTUP}

\section{Simpulan}

Dari hasil analisis yang dilakukan, terdapat efek penggunaan software geogebra pada pemahaman konsep mata kuliah Kapita Selekta Matematika Atas untuk gaya belajar Kinestetik, namun tidak ada efek penggunaan software geogebra pada gaya belajar Visual. Sedangkan untuk gaya belajar Auditori belum bisa dilakukan uji-t karena hanya memiliki satu subjek atau satu datum.

\section{Daftar Pustaka}

Cholifah. 2010. Upaya meningkatkan prestasi belajar dengan model pembelajaran Kooperatif tipe TPS. Skripsi tidak diterbitkan. Surabaya: ADI BUANA.

Greene dan Petty, Developing Language Skill in The Elementary Schools, (Boston : Alyn and Bacon Inc., 1981), hlm. 540-2.

Hohenwarter, M. \& Fuchs, K. (2004). Combination of Dynamic Geometry, Algebra, and Calculus in the Software System Geogebra. Tersedia:
www.Geogebra.org/publications/pec s_2004.pdf.

Hohenwarter. 2008. Teaching and Learning Calculus with Free Dynamic Mathematics Software Geogebra. Mexico: ICME 11.

Kusumah, Yaya S. (2003). Desain dan Pengembangan Bahan Ajar Matematika Interaktif Berbasiskan Teknologi Komputer. Makalah terdapat pada Seminar Proceeding National Seminar on Science and Math Education. Seminar diselenggarakan oleh FMIPA UPI Bandung bekerja sama dengan JICA.

Punaji Setyosari, Metode Penelitian Pendidikan dan Pengembangan, (Jakarta: Kencana)

Sugiyono. 2007. Metode penelitian pendidikan pendekatak kuantitatif, kualitatif, $\quad R \& D . \quad$ Bandung: ALFABETA.

Sukardjo \& Lis Permana Sari. 2009. Metodologi Penilaian Pendidikan Kimia. Yogyakarta: FMIPA UNY

Sugiyono, Metode Penelitian Pendidikan Pendekatan Keuantitatif, Kualitatif, dan $R \& D$ (Bandung: Alfabeta, 2010) 
Surjono, Herman. 2013. Membangun

Course E-Learning Berbasis

Moodle. Yogyakarta: UNY Press.

Suweken. 2011. Pengembangan

Mathlet Matematika Eksploratif untuk meningkatkan Kompetensi Matematika Siswa SMP Kelas VIII di Singaraja. Hasil Penelitian (tidak diterbitkan). Singaraja: Undiksha

Wasis. 2004. Konsep penelitian dan pengembangan. Malang: Universitas Negeri Malang 